\title{
Periampullary cancer and cancer in head of pancreas: What is the difference?
}

\author{
Emeka Ray-Offor* \\ Department of Surgery, University of Port Harcourt Teaching Hospital, Port Harcourt Rivers State, Nigeria
}

\section{Introduction}

The pancreas, a fleshy retroperitoneal organ with mixed exocrine and endocrine function, is not spared of malignant disorders. Malignancies of the pancreas are generally of acinar, ductal or neuroendocrine origin. Majority of these are pancreatic ductal cancer (PDAC) with head of pancreas as the most common site. In the developed world, PDAC is the fourth deadliest malignancy for men and the fifth for women and is predicted to become the second by 2030 [1]. Periampullary cancer is a complex disease of heterogenous origin. This is cancer arising within $2 \mathrm{~cm}$ of the papilla of Vater and include pancreatic, ampullary, biliary and duodenal cancers [2]. Duodenal cancer has the highest estimated 5-year survival (49\%), followed by ampullary cancer (45\%), distal bile duct cancer (27\%), and pancreatic cancer (18\%) [3]. There is some variance in the clinical presentation of periampullary cancer and cancer in the head of pancreas, but the main distinction lies in their cell biology and histology which affect prognosis and outcome. In all, surgical resection involving a pancreaticoduodenectomy is the main stay for curative treatment.

\section{Clinical features}

Based on anatomic location, cancers affecting the periampullary region usually present earlier with biliary tract obstruction resulting in jaundice hence are respectable. Jaundice has a fluctuating pattern due to the temporary relief of bile obstruction from necrosis of this lesion and an ensuing bleed, mixed with acholic stool, leading to silvery stool. Cancer in the head of pancreas is of larger size at presentation with hepatic and hilar metastasis more likely and a progressively deepening pattern of jaundice observed. An excessive accumulation of bile pigment in obstructive jaundice results in pruritus and dark coloured urine. Also, malaise, nausea, weight loss and anaemia are associated features of chronic ailment. Abdominal and /or back pain is a late symptom usually associated with pancreatic cancer which is usually due to neural invasion at the coeliac axis. Other clinical features include late-onset diabetes (within 2 years) and thrombophlebitis migraines. There are no positive clinical features which can clearly identify a group of patients with potentially curable disease nor any simple screen test available.

\section{Tumour biology, histology and outcome}

Periampullary cancer is often preceded by ampullary or duodenal adenomas or known to arise in an adenoma [4,5]. There is a frequent occurrence of periampullary neoplasms in Familial Adenomatous Polyposis (FAP). hence a policy of regular duodenoscopy and biopsy of suspicious lesions following diagnosis of the colorectal polyps [6]. Adenocarcinomas are the predominant histology of periampullary cancers with two subtypes identified by histomolecular tests intestinal and pancreatobiliary types. There is positivity of the transcription factor CDX2, mucin (MUC) 2, CK 20 and CD 10 in the intestinal subtype of cancers whereas MUC $1 \& 4$, CK7\&17 are expressed in the pancreatobiliary subtype [7]. A significant difference in outcome is reported with intestinal type having a better prognosis than the pancreatobiliary type (median overall survival of ampullary cancer 115.5 vs. 16 months; $p<0.001$ respectively) [8]. Epigenetically, KRAS mutation is less seen in ampullary/duodenal cancers compared to pancreatic cancer. Based on morphologic and biological similarity to colorectal cancer the addition of anti-epidermal growth factor receptor (EGFR) treatment in the metastatic and advanced disease is a research focus [9]. Pancreatic cancers have a higher incidence of nodal, neural and vascular invasion compared to periampullary cancers and tend to have a much higher incidence of margin positivity $[10,11]$. Prognosis of malignancies of the pancreas are generally poor. Pancreatic adenocarcinoma has a dismal 5-year survival of 5-20\%, distal cholangiocarcinoma $24 \%$, ampullary carcinoma $34 \%-45 \%$ and duodenal cancer $22 \%-53 \%$ [12].

\section{Investigations}

A prompt abdominal ultrasound to highlight the liver, bile duct and pancreas is a useful baseline investigation on the clinical suspicion of cancer of the pancreas. Follow-up to this, arterial and portal phases of contrast enhanced helical CT scan accurately predicts resectability in $80-90 \%$ of cases [13]. Other important investigations are endoscopic retrograde cholangiopancreatography (ERCP), and/or magnetic resonance (MR), including magnetic resonance cholangiopancreatography (MRCP) and occasionally magnetic resonance angiography (MRA), will accurately delineate tumor size, infiltration, and the presence of metastatic disease in most cases [14]. In centers where available, endosonography and/or laparoscopy with laparoscopic ultrasonography may be appropriate for localization and tissue diagnosis. The detection of occult metastases upstages the cancer with likely alteration in the decision of surgery (Figure 1).

\section{Treatment}

Surgical resection is the only chance for potential cure. The crucial considerations for the surgeon include performance status of the patient, prognosis of the cancer, availability and success of both surgical and nonsurgical management options and patient preferences

${ }^{\star}$ Correspondence to: Emeka Ray-Offor, Department of Surgery, University of Port Harcourt Teaching Hospital, Port Harcourt Rivers State, Nigeria, Tel: +2348052077285; E-mail: erayoffor@yahoo.com

Received: July 05, 2019; Accepted: July 17, 2019; Published: July 22, 2019 


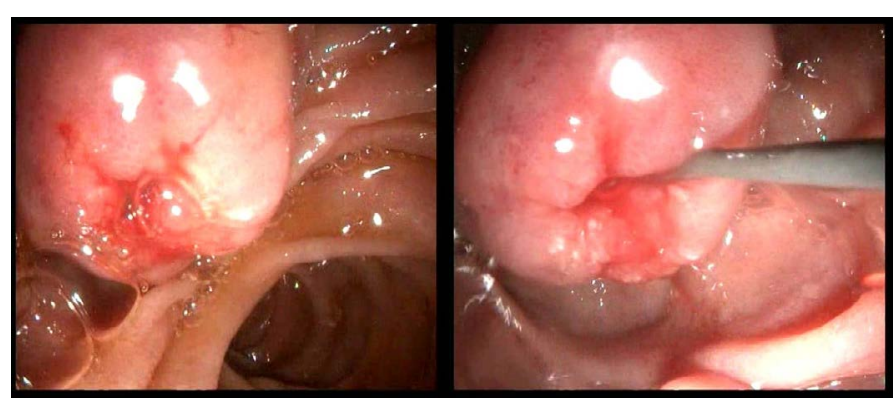

Figure 1. a) Periampullary tumour at duodenoscopy, b) Guidewire cannulation at ERCP

[15]. The preoperative optimization measures include correction of anaemia, combating sepsis, the prevention of renal failure with preoperative mannitol infusion and a good diabetic control. Pancreatic malignancy patients usually are advanced in age thus a good cardiac assessment is needed with haemodynamic optimization before major surgery. There is the need for pain management and respiratory measures to improve outcome of surgery including cessation of smoking, reduction of bronchial secretions [16]. The classical Whipple pancreaticoduodenectomy (PD) is the favoured surgical choice for resectable periampullary and cancer head of pancreas. This involves en bloc resection of the distal stomach, duodenum, distal common bile duct, gall bladder, head of the pancreas and adjacent lymph nodes and enteric reconstruction. Extended resections involving the portal vein or total pancreatectomy are sometimes performed; however, these do not increase survival thus a preoperative detection of portal vein encasement does not justify interventional resection [14]. A modification of PD surgery is the preservation of the pylorus which offers technical advantages (ease and speed) and may provide better quality of life and may prevent the occurrence of postgastrectomy syndromes [17]. Also, Laparoscopic PD has attracted a recent surge of interest with short-term advantages within blood loss, postoperative morbidity and comparable oncological and longterm survival outcomes $[18,19]$. The post-pancreaticoduodenectomy hospital mortality in high volume centers is in the single digit range but morbidity remains high [20]. There are conflicting reports of benefit from the administration of adjuvant chemotherapy with gemcitabine and radiotherapy [21,22]. However, unresectable locally advanced disease who receive treatment with chemo-radiation have median survival ranging from 11-15 months [13]. In patients having locally advanced cancers with good performance status, an operative biliary-enteric bypass is performed. Palliative care includes surgical, endoscopic and other palliative techniques. The surgical options for relief of obstructive jaundice include roux-en-Y hepatico- or choledochojejunostomy and a gastrojejunostomy for duodenal or gastric outlet obstruction. Endoscopic stenting with plastic or selfexpanding metal stents depends on projected duration of survival. Also, wide lumen self-expanding metal stents can be used to relieve gastric outlet obstruction. The relief of pain due to invasion of the celiac plexus by injecting ethanol or a local anaesthetic to either side of the aorta at the level of celiac axis can be performed intraoperative, percutaneous, endoscopic ultrasound guided or thoracoscopic. Other palliative measures involve nutrition, pancreatic enzyme replacement and prophylaxis/treatment of venous thromboembolic (VTE) disease.

\section{Conclusion}

The tumour biology and histology are distinct predictors of outcome in periampullary and PDAC. An early detection and surgical resection are the only hope for cure for these cancer patients. Pancreaticoduodenectomy a complex surgery remains the treatment of choice; with advances in anaesthesia, surgical technique and critical care there is a reduced outcome of pancreatic surgeries in high volume referral centers.

\section{References}

1. Siegel RL, Miller KD, Jemal A (2015) Cancer statistics, 2015. CA Cancer J Clin 65 5-29. [Crossref]

2. Sarmiento JM, Nagomey DM, Sarr MG, Farnell MB (2001) Periampullary cancers: are there differences? Surg Clin North Am 81: 543-555. [Crossref]

3. He J, Ahuja N, Makary MA, Cameron JL, Eckhauser FE, et al. (2014) 2564 resected periampullary adenocarcinomas at a single institution: trends over three decades. $H P B$ (Oxford) 16: 83-90. [Crossref]

4. Jagelman DG, Decosse JJ, Bussey HJR (1988) Upper gastrointestinal cancer in familial adenomatous polyposis. Lancet 1: 1149-1151. [Crossref]

5. Spigelman AD, Talbot IC, Penna C, Nugent KP, Phillips RK, et al. (1994) Evidence for adenoma-carcinoma sequence in the duodenum of patients with familial polyposis. $J$ Clin Pathol 47: 709-710. [Crossref]

6. Groves CJ, Saunders BP, Spigelman AD, Phillips RK (2002) Duodenal cancer in patients with familial adenomatous polyposis (FAP): results of a 10-year prospective study. Gut 50: 636-641. [Crossref]

7. Kawabata $Y$, Tanaka T, Nishisaka T, Inao T, Nishi T, et al. (2010) Cytokeratin 20 (CK20) and apomucin 1 (MUC1) expression in ampullary carcinoma :correlation with tumour progression and prognosis. Diagn Pathol 5: 75. [Crossref]

8. Chang DK, Jamieson NB, Johns AL, Scarlett CJ, Pajic M, et al. (2013) Histomolecular phenotypes and outcome in adenocarcinoma of the ampulla of vater. J Clin Oncol 31: 1348-1356. [Crossref]

9. Lièvre A, Bachet JB, Le Corre D, Boige V, Landi B, et al. (2006) KRAS mutation status is predictive of response to cetuximab therapy in colorectal cancer. Cancer Res 66: 3992-3995. [Crossref]

10. Sommerville CA, Limongelli P, Pai M, Ahmad R, Stamp G, et al. (2009) Surviva analysis after pancreatic resection for ampullary and pancreatic head carcinoma: an analysis of clinicopathological factors. J Surg Oncol 100: 651-656. [Crossref]

11. Tol JA, Brosens LA, van Dieren S, van Gulik TM, Busch OR, et al. (2015) Impact of lymph node ratio on survival in patients with pancreatic and periampullary cancer. $\mathrm{Br}$ J Surg 102: 237-245. [Crossref]

12. Yeo CJ, Cameron JL, Sohn TA, Lillemoe KD, Pitt HA, et al. (1997) Six hundred fifty consecutive pancreaticoduodenectomies in the i990s. pathology, complications and outcome. Ann Surg 226: 248-260. [Crossref]

13. McCarthy MJ, Evans J, Sagar G, Neoptolemus JP (1998) Prediction of resectability of pancreatic malignancy by computed tomography. Br J Surg 85: 320-325. [Crossref]

14. Johnson CD (2005) Guidelines for the management of patients with pancreatic cancer periampullary and ampullary carcinomas. Gut 54: v1-v16. [Crossref]

15. Myatra S, Divatia JV, Jibhkate B, Barreto GS, Shrikhande SV (2011) Preoperative assessment and optimization in periampullary and pancreatic cancer. Indian J Cancer 48: 86-93. [Crossref]

16. Perone JA, Riall TS, Olino K (2016) Palliative Care for Pancreatic and Periampullary Cancer. Surg Clin North Am 96: 1415-1430. [Crossref]

17. Diener MK, Fitzmaurice C, Schwarzer G, Seiler CM, Hüttner FJ, et al. (2016) Pyloruspreserving pancreaticoduodenectomy ( $p$ p Whipple) versus pancreaticoduodenectomy (classic Whipple) for surgical treatment of periampullary and pancreatic carcinoma. Cochrane Database Syst Rev 11: CD006053. [Crossref]

18. Gagner M, Pomp A (1994) Laparoscopic pylorus-preserving pancreatoduodenectomy Surg Endosc 8: 408-410. [Crossref]

19. Chen K, Liu XL, Pan Y, Maher H, Wang XF (2018) Expanding laparoscopic pancreaticoduodenectomy to pancreatic head and periampullary malignancy: major findings based on systematic review and meta-analysis. BMC Gastroenterol 18: 102. [Crossref] 
20. Winter JM, Brennan MF, Tang LH, D’ Angelica M, Dematteo RP, et al. (2012) Survival after resection of pancreatic adenocarcinoma: results from a single institution over three decades. Ann Surg Oncol 19: 169-175. [Crossref]

21. Balachandran P, Dimri K, Rastogi N, Kumar A, Saxena R, et al. (2005) Adjuvant chemoradiotherapy in ampullary cancers. Eur J Surg Oncol 31: 158-163.
22. Klinkenbijl JH, Jeekel J, Sahmoud T, van Pel R, Couvreur ML, et al. (1999) Adjuvant radiotherapy and 5-fluorouracil after curative resection of cancer of the pancreas and periampullary region: phase III trial of the EORTC gastrointestinal tract cancer cooperative group. Ann Surg 230: 776-782. [Crossref]

Copyright: (C2019 Ray-Offor E. This is an open-access article distributed under the terms of the Creative Commons Attribution License, which permits unrestricted use, distribution, and reproduction in any medium, provided the original author and source are credited. 